\title{
ESTIMATION OF CROPPED AREA AND IRRIGATION WATER REQUIREMENT USING REMOTE SENSING AND GIS
}

\author{
R. Ahsen ${ }^{1}$, Z. M. Khan ${ }^{1}$, H. U. Farid ${ }^{1}$ and A. Shakoor ${ }^{1}$ and I. Ali ${ }^{2}$ \\ ${ }^{1}$ Department of Agricultural Engineering, Bahauddin Zakariya University, Multan-Pakistan; \\ ${ }^{2}$ Department of Environmental Engineering, College of Environmental Science and Engineering, Ocean University of \\ China, Qingdao, China \\ *Corresponding author’s email: farid_vjr@yahoo.com; zahidmk@bzu.edu.pk
}

\begin{abstract}
Land use-land cover (LULC) mapping has immerged as a useful and important Remote Sensing (RS) and Geographic Information System (GIS) technique for improving the management of natural resources for the progress of a country like Pakistan. Therefore, a research study was conducted to develop LULC maps for the District of Multan, Pakistan. For this purpose, economically available multi temporal (time series) images with acceptable resolution from satellite (LANDSAT 7 ETM+) were obtained for Rabi and Kharif season of 2011-12 to perform supervised classification and identification of crops in the study area. Image Processing was performed in ERDAS Imagine 2011 version for obtaining the high-class time series normalized difference vegetation indices (NDVI) for each LANDSAT 7 imagery. Four classes were targeted for crops out of the seven clusters created using target crop signatures with $95 \%$ maximum likely-hood. The resulting crop types were validated by 86 ground truthing points. Over all $74 \%$ efficiency was found using error matrix technique. The regional irrigation water requirements of specific crops were estimated using the generated LULC maps of exerted crop area. The calculated cropped areas through ArcGIS 9.3 version were of 0.226 Mha for cotton, 0.207 Mha for wheat, 0.014 Mha for rice and 0.007 Mha for sugarcane. The total regional crop water requirement of the study area was of $1653.62 \mathrm{Mm}^{3}$ for cotton, $911.25 \mathrm{Mm}^{3}$ for wheat, $97.93 \mathrm{Mm}^{3}$ for rice and $112.25 \mathrm{Mm}^{3}$ for sugarcane. The LULC mapping technique should be used to develop a decision support system for water, land and other natural resources management at regional scale for efficient resource utilization and sustainable development.
\end{abstract}

Keywords: LULC, LANDSAT 7, Time-series analysis, NDVI, Classification, Crop area mapping, Crop water requirement.

https://doi.org/10.36899/JAPS.2020.4.0103

Published online April 25, 2020

\section{INTRODUCTION}

Reliable information of water and land requirements for agricultural production is much needed when freshwater resources are getting scarce. Study of irrigation system performance is often restricted by practical limitations on the amount of data that can be collected in the field. Land use land cover (LULC) data can be useful for the hydrological modeling for irrigation scheduling at regional scale (Rawat and Singh 2017; Koneti et al. 2018; Shrestha 2019). The LULC data can also be used to estimate the groundwater charging, infiltration rate which are directly associated with irrigation water (Jin et al., 2019). The term Land Use (LU) is distinct from Land Cover (LC). LU refers to the purpose the land serves; while LC refers to the topography of earth crust for example vegetation, urban infrastructure, water, bare soil and desert. Thus, the combination of LU and LC classes on the map termed as LULC map (Cheema and Bastiaanssen, 2010). The LULC of the earth is shifting noticeably due to anthropogenic activities. So, it is necessary to investigate the LULC changes to make a sustainable land utilization plan. Usually different ecological, demographic, and socioeconomic settings assist to develop land use practices. This setting frequently varies and has a direct effect on land cover (Muttitanon and Tripathi, 2005).

Many researchers suggest the use of time series remotely sensed images for different intention such as crop identification, crop area estimation and crop yield (Coppin et al., 2004) and now crop classification using remote sensing has become an active research topic (Song et al., 2017). However, identification of crops using remote sensing data is still a challenge due to diverse change in cropping patterns and small farm sizes (Waldner et al., 2016). Advanced remotely sensed images now permit to calculate the paddock point and area estimation (Barrett et al., 2000). LANDSAT 5 imagery has been used for the measurement of cropland areas (Chemin et al., 2004), crop identification (Toomanian et al., 2004) and LULC classification (Aplin and Atkinson, 2001).

The LULC can also be used to quantify irrigation input based on the agricultural crop types. Similarly, estimation of fine-scale changes in agricultural LU are paramount important for a global as well as 
regional and local perspective. Hassan et al. (2016) used the satellite images to quantify the LULC changes in Islamabad, Pakistan. It was concluded that rapid deforestation and urbanization have a wide range of environmental impacts. Similarly, Shrestha (2019) analyzed the LULC changes using the LANDSAT image in Pampanga River basin Philippines and reported that the flood runoff, volume and inundation areas may increase in the future due to LULC change. Usman et al. (2016) reported that spatio-temporal LULC classification and their seasonal variation provide useful information for establishing realistic LULC scenarios for hydrological studies. Furthermore, the accurate and timely cropland classification maps provide the decision-making applications to local authorities as well as government agencies like monitoring of drought, yield production, crop insurance, commodity market, and supply chain (Fan et al. 2007; Lobell et al., 2015; Cai et al., 2018). So, recently improved data sets of LULC are useful for an agricultural region like Multan, Pakistan.

In estimation of cropped areas and water requirements for major crops has a significant contribution to water resources supremacy. This is especially true in regions where ground-based data collection systems are too weak and inaccurate. Such data can also contribute to increase the water use efficiencies in agriculture. Keeping in view, the study was conducted to estimate the cropped area and resulting irrigation water requirement for major crops of District Multan, Pakistan using RS and GIS technique.

\section{MATERIALS AND METHODS}

Study Area: The study was conducted for the District Multan, Punjab, Pakistan. It is located at latitude of $30^{\circ} 11^{\prime} 52^{\prime \prime} \mathrm{N}$ and longitude of $71^{\circ} 28^{\prime} 11^{\prime \prime} \mathrm{E}$ and at an elevation of $122 \mathrm{~m}$ (Figure 1). The Sidhnai canal is the main canal for the supply of irrigation water for the District Multan with gross command area of $0.349 \mathrm{Mha}$ (ADB, 2006).

Climate: The study area has four seasons i.e. winter, spring, summer and autumn. The maximum coldness is observed in December and January with minimum temperature of $4.8^{\circ} \mathrm{C}$ and maximum temperature of $23.4^{\circ} \mathrm{C}$. The maximum sunshine is observed in June and July with maximum temperature $47^{\circ} \mathrm{C}$ and minimum temperature $26^{\circ} \mathrm{C}$. Multan district is in arid region with average rainfall is about $200 \mathrm{~mm} /$ year and more than $50 \%$ of rainfall occurred in July and August.

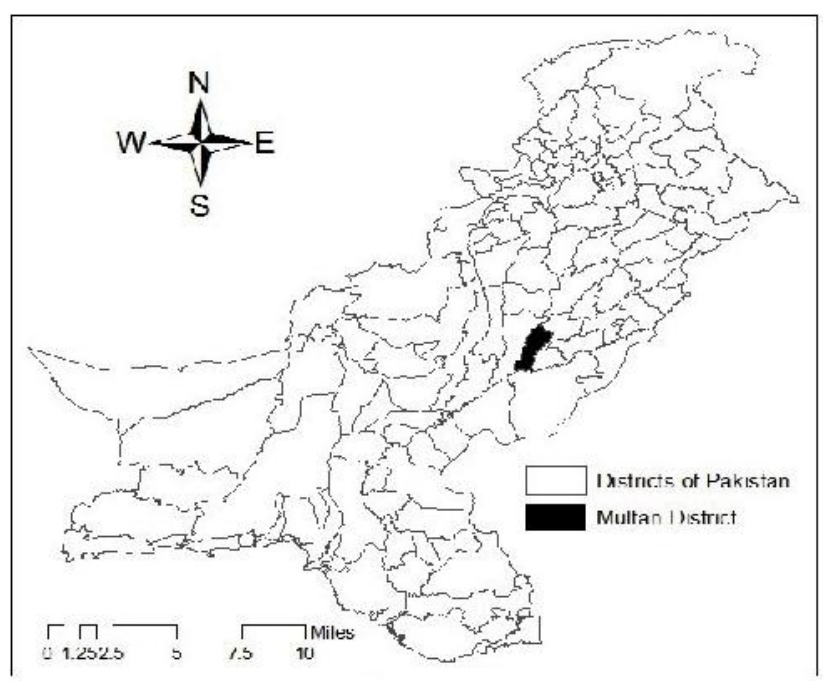

Figure 1: Location of study area

Cropping pattern: In study area, there are mainly two cropping seasons i.e. Kharif and Rabi. The cotton is the most prominent and cash crop of Kharif season; however, wheat is the major crop for the Rabi season. The area is cultivated under following cropping patterns such as cotton-wheat, rice-wheat and sugarcane-wheat-cotton. The major area of the Multan district follows the cottonwheat cropping pattern. However, the cropping pattern is shifting to rice-wheat and sugarcane-wheat-cotton due to high production cost of cotton and change in climatic conditions.

Data Acquisition: The data of remotely sensed imagery of LANDSAT 7 ETM+ was acquired from the glovis.usgs.gov. The LANDSAT 7 ETM+ is the seventh satellite of the LANDSAT program. The LANDSAT 7 ETM + is equipped with enhanced thematic mapper plus (ETM+). At an altitude of $705 \mathrm{~km}$, the LANDSAT 7 ETM+ scans full surface in 232 turns or 16 days. Similarly, the data regarding the metrological parameters, agricultural census, cropping pattern, soil type, crop type, irrigated area, crop phenology and crop calendar were collected from the respective departments as given in Table 1.

Processing and Analyses of Satellite Data: The shape file of study area was created by importing the global positioning system (GPS) points of training data in Arc GIS 9.3 version. This shape file was used to create digitized polygons. Classification and identification of land use was executed using these polygons and GPS training data. The ERDAS imagine software 2011 version was used to perform gap fillings in the images, layer stacking and mosaicing. The NDVI analysis was performed which further used in mapping of LU. Supervised classification was performed by using crop signatures to identify the crops. The crop signature file was created using the GPS training points and polygons. 
Gap filling procedure in images: LANDSAT 7 ETM+ images after 2003 have the gaps due to the failure of scanner line corrector. Many techniques have been developed to fill these gaps like histrogram match, neighborhood similar pixel interpolator, geostatistical neighborhood similar pixel interpolator (Liu et al., 2018; Garcia et al., 2019). The image which is used to fill the gaps in primary image is called secondary (USGS, 2004). Model maker of ERDAS imagine 2011 version was used to add each band of secondary image to corresponding band in primary image (Imagine, 2006). The gap in band of image that was taken on 12-5-2011 was filled by the band of image that was taken on 28-5-2011. The image is before and after gap filling is shown in Figure 2.
Layer stacking and subset satellite images: To obtain single image of multi bands all seven bands were stacked. The final image was used for crop identification and cropped area map development. The study area falls under two tiles of LANDSAT 7 ETM+ images which was 39 and 40. The two tahsils of Multan District, Multan city and Multan Sadar fall in 39 tiles while, half part of Shujabad and tahsil Jalalpur Pirwala fall in tile 40. To combine these two images, mosaicing process was done (Figure 3). The mosaic image enclosed a large area and so, the desired study area was extracted using subset command.

Table 1 Acquired Data \& Sources

\begin{tabular}{lll}
\hline Type \& Source & Data Components & Data Specifications \\
\hline $\begin{array}{l}\text { Satellite Data } \\
\text { (glovis.usgs.gov) }\end{array}$ & LANDSAT 7 ETM imagery & 30 m resolution, \\
$\begin{array}{l}\text { Metrological Data } \\
\text { (Pakistan Metrological Department, }\end{array}$ & $\begin{array}{l}\text { Precipitation, Temp, wind speed, } \\
\text { Humidity \& }\end{array}$ & All data on daily bases for years 2011 \\
Islamabad) & $\begin{array}{l}\text { Sunshine hours. } \\
\text { Agriculture Data } \\
\text { (Survey \& Concerned Agricultural }\end{array}$ & Agricultural census data, Crop \\
Departments) & Calendar, Crop Coefficient, Crop & For years 2011 and 2012 \\
\hline
\end{tabular}

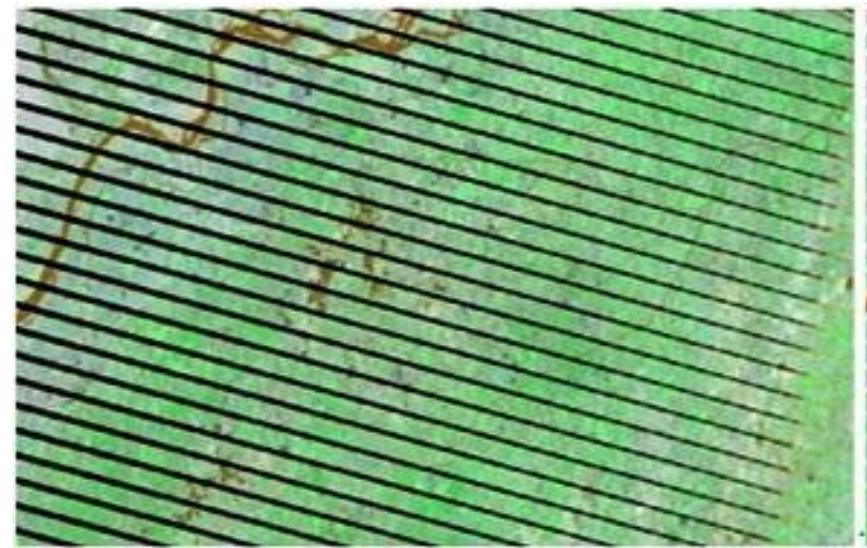

Figure 2. Landsat image before and after gap filling
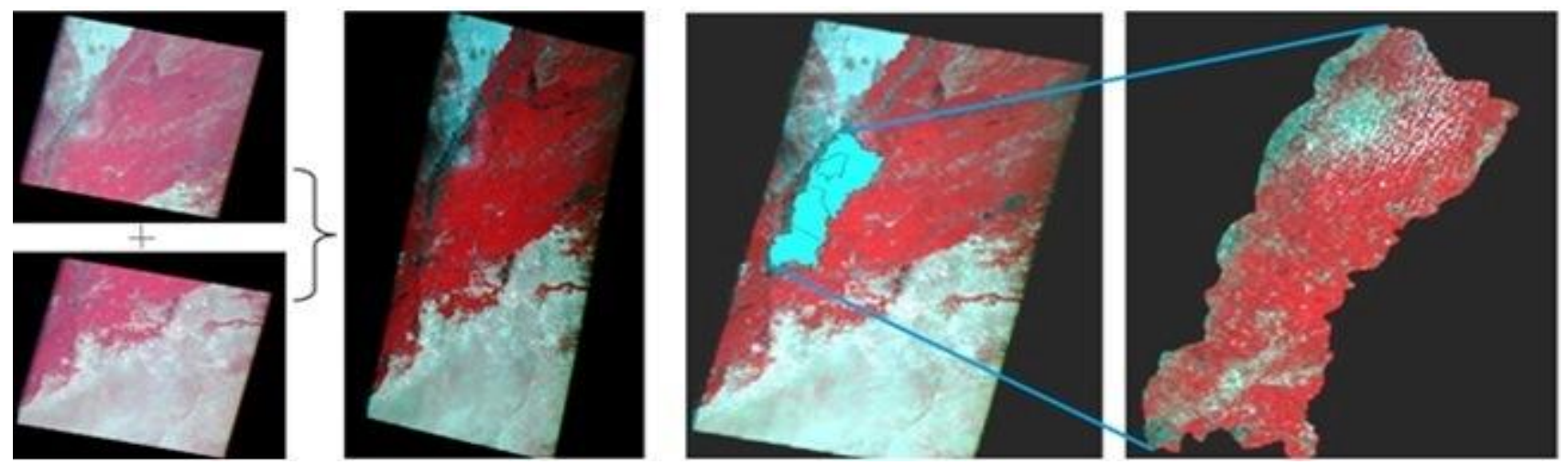

Figure 3 Mosaicing and subseting of LANDSAT 7 ETM+ images 
Normalized Difference Vegetation Indexing (NDVI): The NDVI (Normalized Difference Vegetation Index) is the indicator of plant health based on how much light absorb and reflect by the plant (Li et al., 2019). NDVI class signatures are matchless spectral properties of a class which can be plotted. The process was performed in unsupervised classification. The mosaic images were used as input file for the formation of NDVI value images.

Supervised classifications: The data collected through field survey were used to perform supervised classification on LANDSAT 7 ETM+ images for the both
Kharif 2011 and Rabi 2011-2012 seasons. The signature auditor based on pixel value for each crop was created using these data points. The exact time of crop sowing, harvesting and information about crop development stage was essential to acquire the correct image. The crop calendar of study area is shown in Table 2. Supervised classification showed that the analyst influences the outcomes using the signature file as a sample of known identity (i.e., pixels previously allocated to classes) to classify pixels of the unidentified characteristics (i.e., to allocate unclassified pixels to one of the many identified classes).

Table 2 Crop calender for study area.

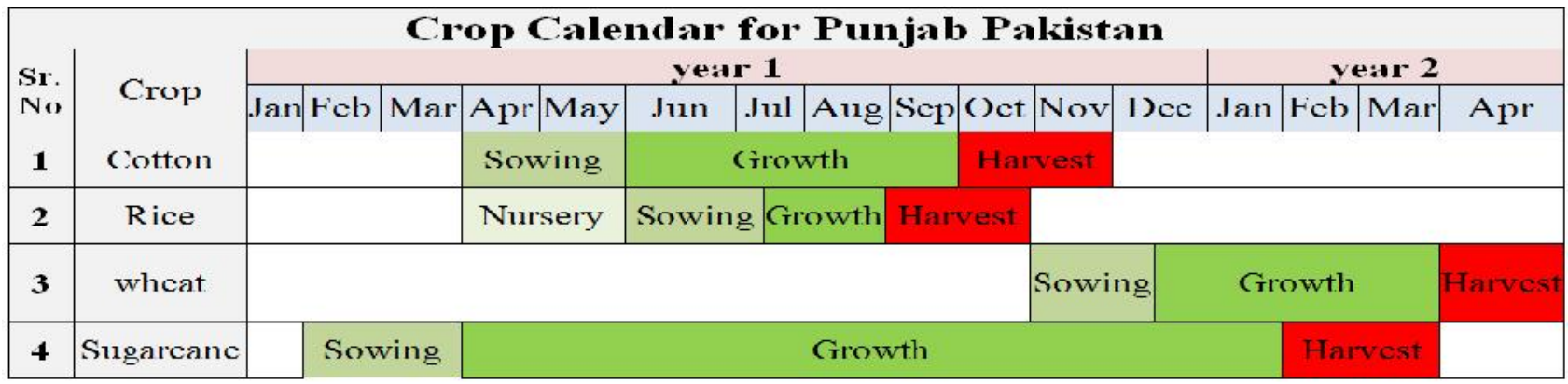

Extraction of crop area using ArcGIS 9.3 vs: The area was calculated from attribute table by counting the pixels of each crop in ArcGIS 9.3vs. The unique values and colures were assigned to different crops for showing on LULC map.

Maps validation and accuracy assessment: The accuracy and consistency of LU classes was found based on the accuracy assessment by ground truthing survey. The sample point's readings were taken with the Garmin model GPS 60 . The $60 \%$ governing class was selected as the specific LU class. The error matrix technique was used to find the accuracy.

Estimation of Irrigation Water Requirement: Metrological data consisted of minimum and maximum temperature, sunshine hours, wind speed, pan evaporation, rainfall and relative humidity were used to estimate reference evapotranspiration (ETo) using Hargreaves Samani equation (Hargreaves and Samani, 1985; FAO, 2001), shown in Figure 4. The CWR was calculated by multiplying ETo and crop coefficient $(\mathrm{Kc})$ value (10 daily) of specific crop (Ullah et al., 2001; Turner et al., 2010). Kc values of each crop were selected based on crop development stage, shown in Figure 5. The total irrigation water requirement (IWR) was calculated by multiplying the total area of specific crop with the crop water requirement of corresponding crop.

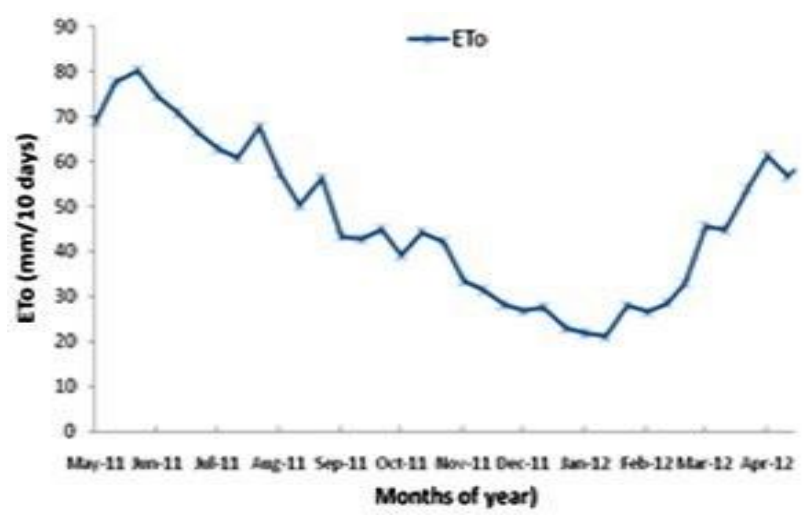

Figure 4 ETo for study area

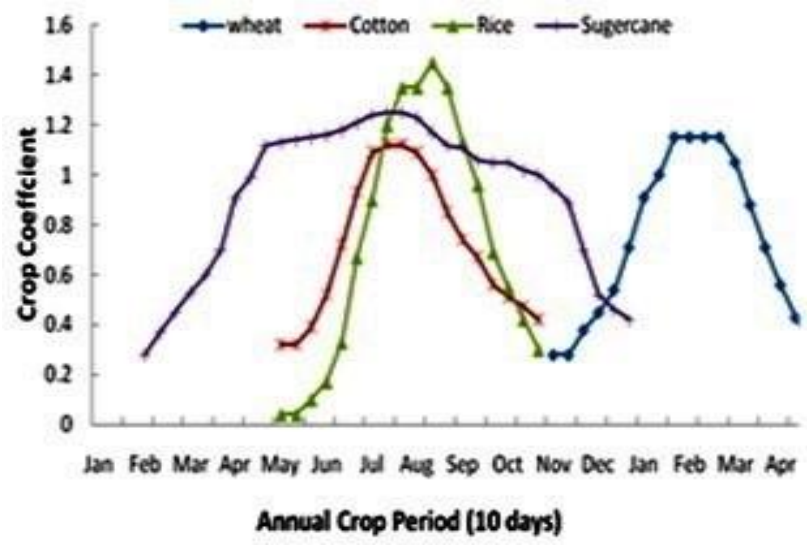

Figure 5 Kc curve for study area 


\section{RESULTS AND DISCUSSION}

The satellite images cannot be used directly to form LULC maps because these datasets are in raw form and not available for any specific study. So, these datasets are initially processed in ERDAS Imagine and prepared for desired kind of study to find the results. The NDVI maps were created for the distinguish among desired crop classes. It has been reported that the identification of phenological pattern of different crops using NDVI profiles is a powerful tool for the crop classification (Panigrahy et al., 2010).

Cropped Area of each Crop: The final areal extent of each crop resulting through supervised classification is given in Figures 6 to 11. The calculated cropped area for District Multan through ArcGIS 9.3 version was of 0.226 Mha for cotton, 0.207 Mha for wheat, 0.014 Mha for rice and 0.007 Mha for sugarcane. According the Punjab Government Statistics in Multan, the area under cotton cultivation for the year of 2011-2012 was more than 0.180 Mha. Similarly, the area under wheat, Rice and Sugarcane was more than 0.173, 0.011 and 0.003 Mha, respectively (Waldner et al., 2016). The resolution of LANDSAT 7 ETM allows one pixel to capture the $22 \%$ of 0.40 ha which gave precise result even for 0.40 ha have different crops. According to the survey of National Engineering Services of Pakistan (NESPAK), more than $83 \%$ formers have the land less than 4 ha. Multan is totally irrigated area and major irrigation source of this area is Sidhnai canal. The 70 to $80 \%$ irrigation requirement is fulfilled by this canal water and rest is fulfilled by groundwater which is 20 to $25 \%$ (GoP, 2010).

Ground Truthing of Identified Crops: An error matrix is a very effective way to represent accuracy. To illustrate the precision of the research, the error matrix techniques were used (Campbell, 2008). The accuracy of the crop points, which were taken during field survey in study area shown in Table 3. The number of grounds truthing points were selected on average cropped area size of region. Total 24 points were selected to validate the cotton crop, 14 for rice, 39 for wheat and 9 for sugarcane. The maximum accuracy was achieved in cotton crop which was $79 \%$. The 74, 71, $44 \%$ accuracies were achieved for wheat, rice and sugarcane, respectively. The low accuracy of sugarcane was due to the misclassification of sugarcane pixel to wheat class in spring because of very early growth of crop when satellite images were acquired. however, user accuracy metric showed relatively similar values to producer accuracy (Joseph, 2005; Asgarian et al., 2016).

Irrigation Water requirement: The accurate and precise irrigation water estimation requires the knowledge of crop water requirement which is directly associated with evapotranspiration and LC. The average crop water requirement in the area is $620,480,1500$, and $1800 \mathrm{~mm}$ for cotton, wheat, rice and sugarcane, respectively (FAO, 2012). In Pakistan, major crops like wheat and rice are planted on flat basin. This sowing practice need higher irrigation water requirement due to enormous losses like evaporation and percolation (Rehman et al., 2015). The available surface water can only irrigate 6.35 Mha in Pakistan while 12.53 Mha are irrigated using groundwater (GOP, 2012). The monthly measured irrigation water requirement for cotton, rice, wheat and sugarcane during 2011-12 is shown in Figure 12. Total irrigation requirements for cotton, wheat, rice and sugarcane crop were found to be $1653.62,911.25$, 97.93 and $112.25 \mathrm{Mm}^{3}$, respectively. The month of peak irrigation requirement was July for cotton, August for Rice, March for wheat and May for sugarcane. June is the hottest but driest month of pre-monsoon season in which less than $10 \mathrm{~mm}$ rainfall was recorded. The evapotranspiration increases sharply due to high intensity of heat. About $80 \mathrm{~mm}$ of rainfall was occurred from monsoon in month of July. Due to high vegetative growth and maximum cultivated area, the water requirement was high in end of July, the similar results were reported by Naheed and Rasul, 2010. According to an estimation, during the year 2011-2012, $10 \%$ less canal water was available as compared to previous average (GoP, 2016). In August, the heavy precipitation occurred due to monsoon which has immense value for the former. The evapotranspiration level was comparatively low due to high relative humidity and low intense solar radiation. The water requirement condition remains satisfactory due to about $100 \mathrm{~mm}$ rainfall, but crop required proper irrigation. The monsoon air mass recedes in September which causes the sharply decrease in rainfall. Due to the smaller day and low air temperature, the evaporative demand also decreases.

The monthly irrigation water requirements for the study area were maximum in June $\left(363.79 \mathrm{Mm}^{3}\right)$, July (516.45 $\left.\mathrm{Mm}^{3}\right)$ and August (399.84 $\mathrm{Mm}^{3}$ ), as shown in Figure 13. The seasonal irrigation water demand for Kharif and Rabi was 1834.99and 940.09 $\mathrm{Mm}^{3}$, respectively. The total estimated irrigation water requirement (IWR) of the study area was of $2775.05 \mathrm{Mm}^{3}$ for the both Kharif and Rabi 2011-2012 seasons. The efficient management and conservation of existing water resources can fulfill the required amount of water. In the month of June, July and August when water requirement is high, the full supply in canal commands areas can decrease the water deficiency. Increased groundwater exploitation in high-recharge areas can also help in fulfilling the irrigation water requirement. 


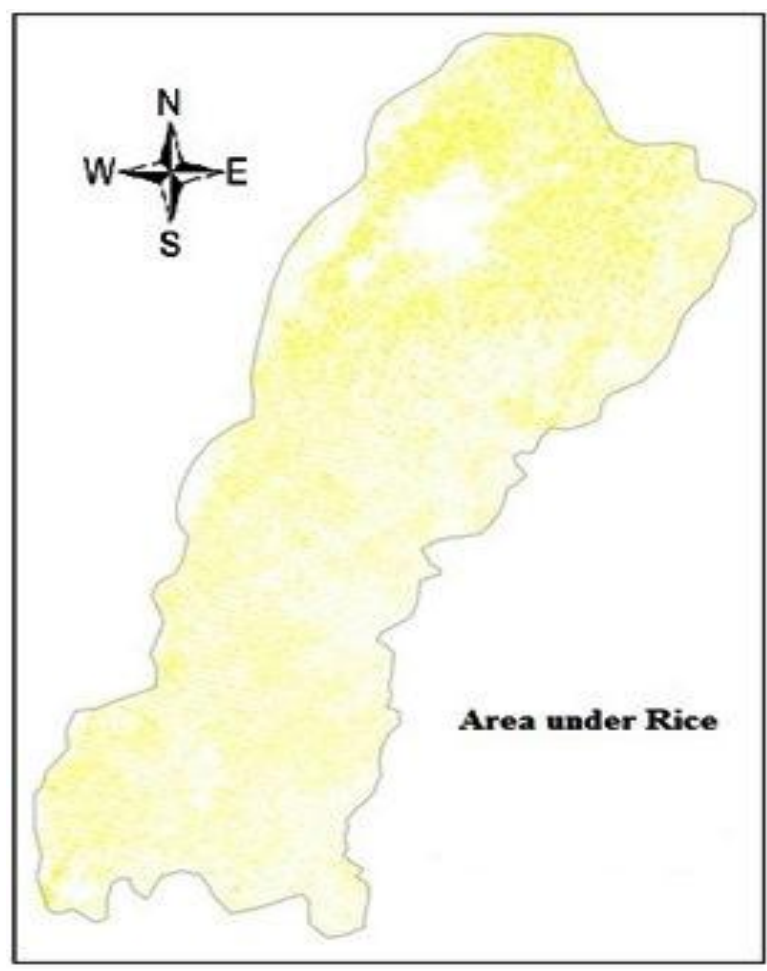

Figure 6. Land use map for rice

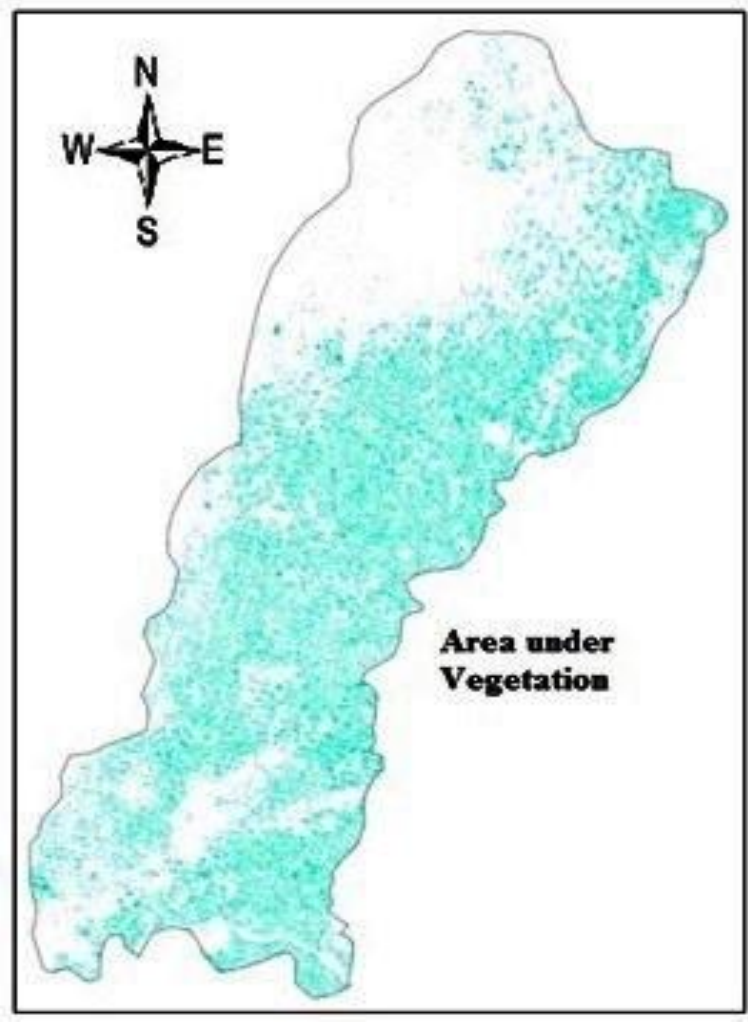

Figure 8. Land use map for vegetation

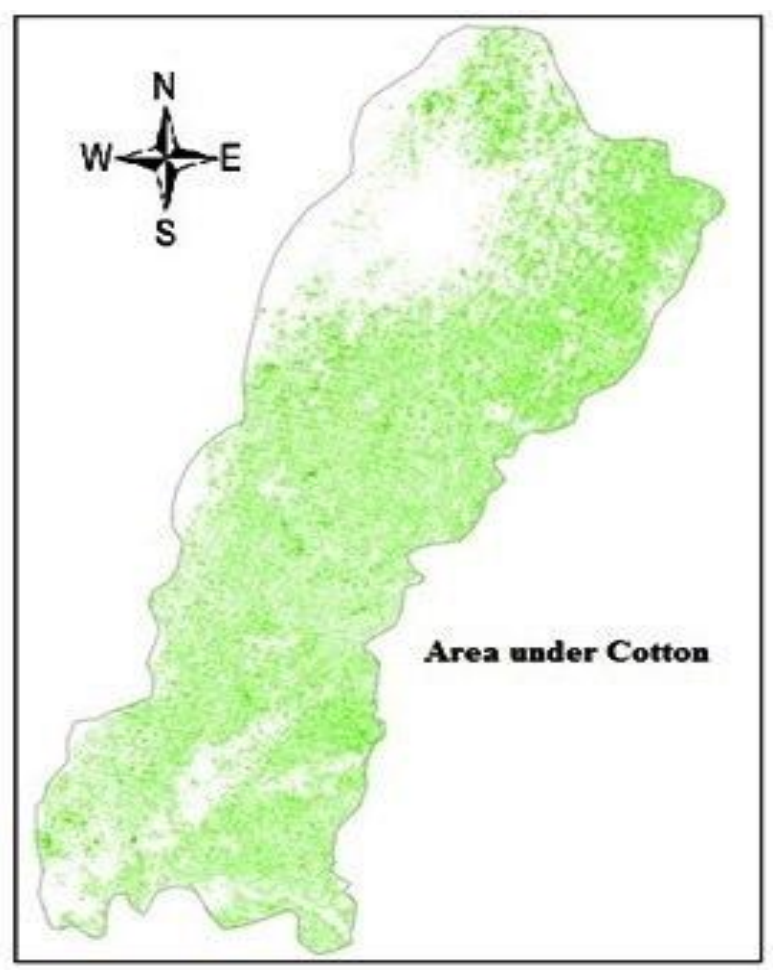

Figure 7. Land use map for cotton

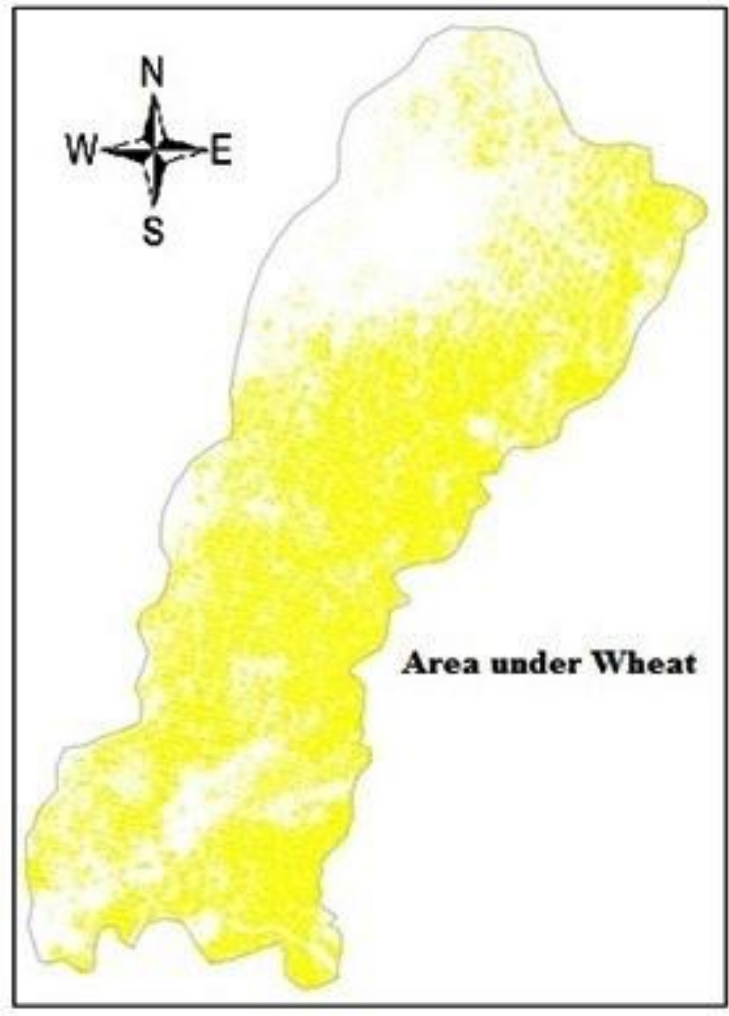

Figure 9. Land use map for wheat 


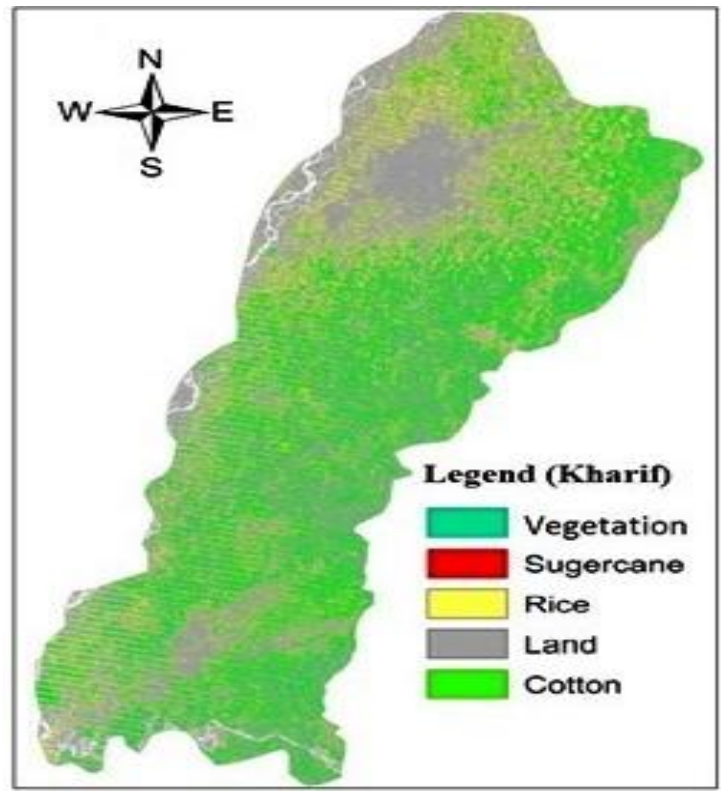

Figure 10. LULC map for Kharif

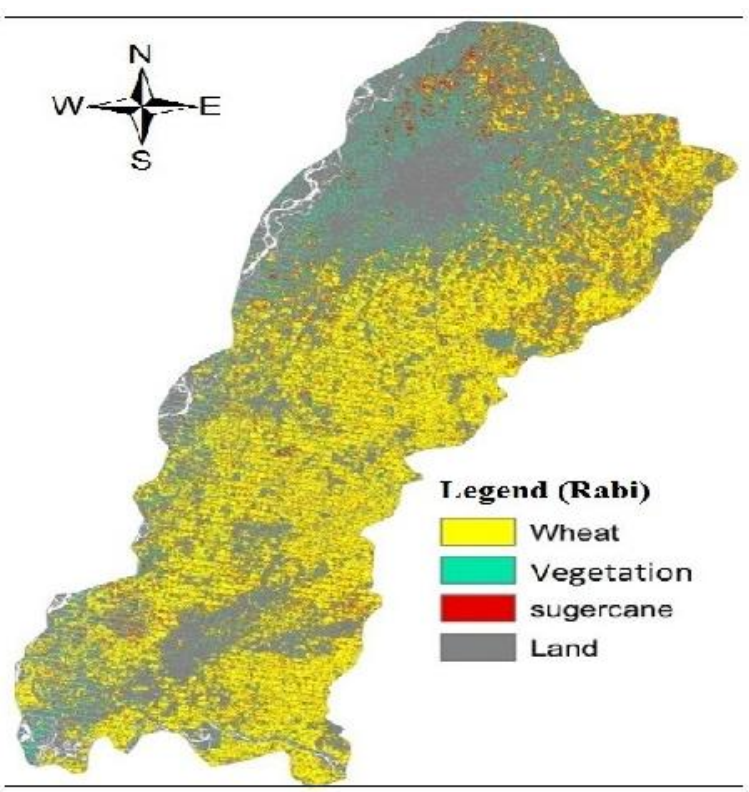

Figure 11. LULC map for Rabi season

Table 3. Ground truthing accuracy for LULC map.

\begin{tabular}{clccccccc}
\hline Sr. No & Crop & Cotton & Rice & Wheat & Sugarcane & Veg* & Land & Accuracy \% \\
\hline 1 & Cotton & 19 & 2 & 0 & 1 & 1 & 1 & 79 \\
2 & Rice & 3 & 10 & 0 & 0 & 0 & 1 & 71 \\
3 & Wheat & 0 & 0 & 29 & 6 & 2 & 2 & 74 \\
4 & Sugarcane & 1 & 0 & 2 & 4 & 2 & 0 & 44 \\
5 & Vegetation & 2 & 1 & 2 & 2 & 17 & 0 & 71 \\
6 & Land & 1 & 1 & 2 & 1 & 2 & 33 & 82 \\
\hline
\end{tabular}
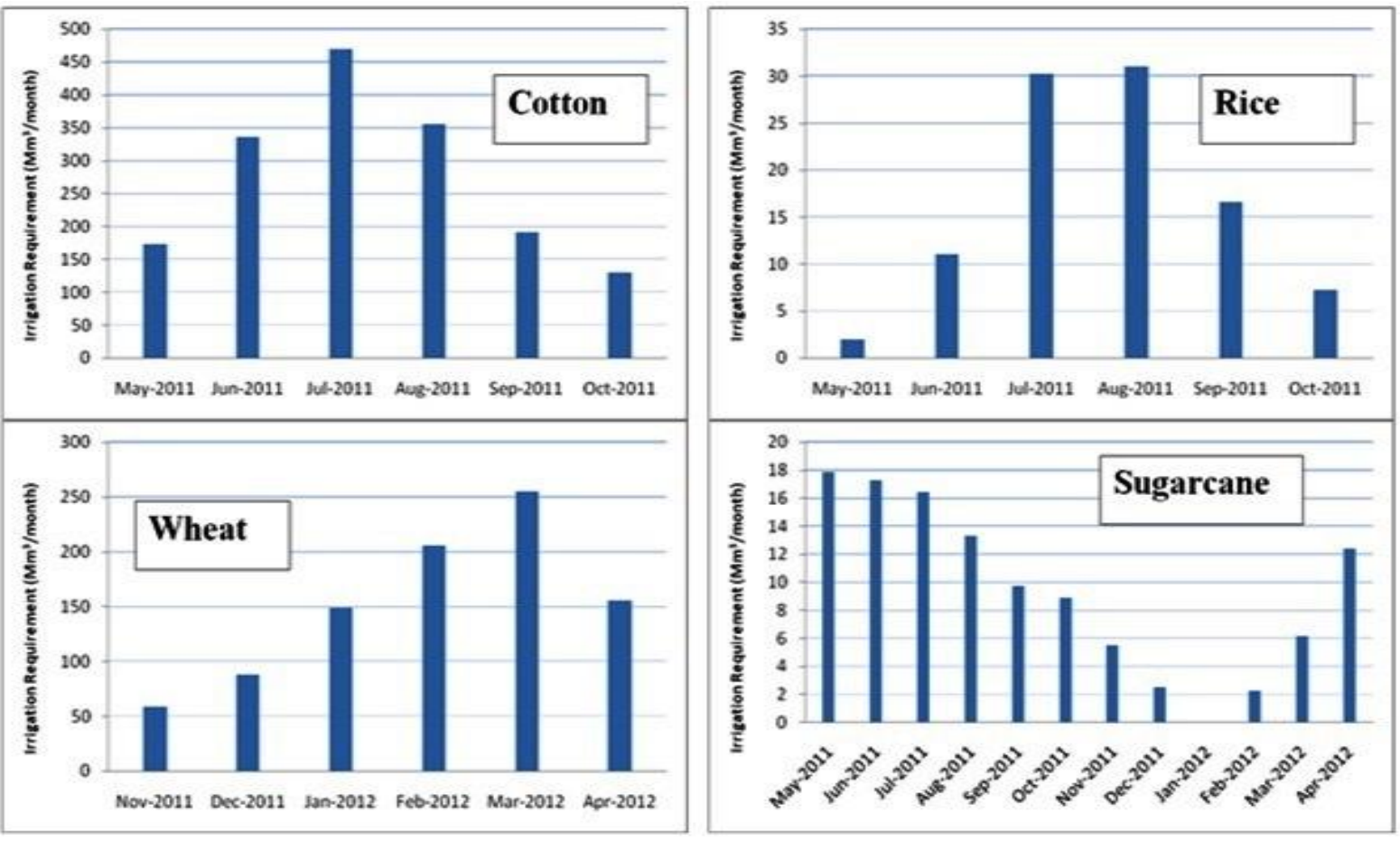

Figure 12. Estimated crop water requirement for each crop. 

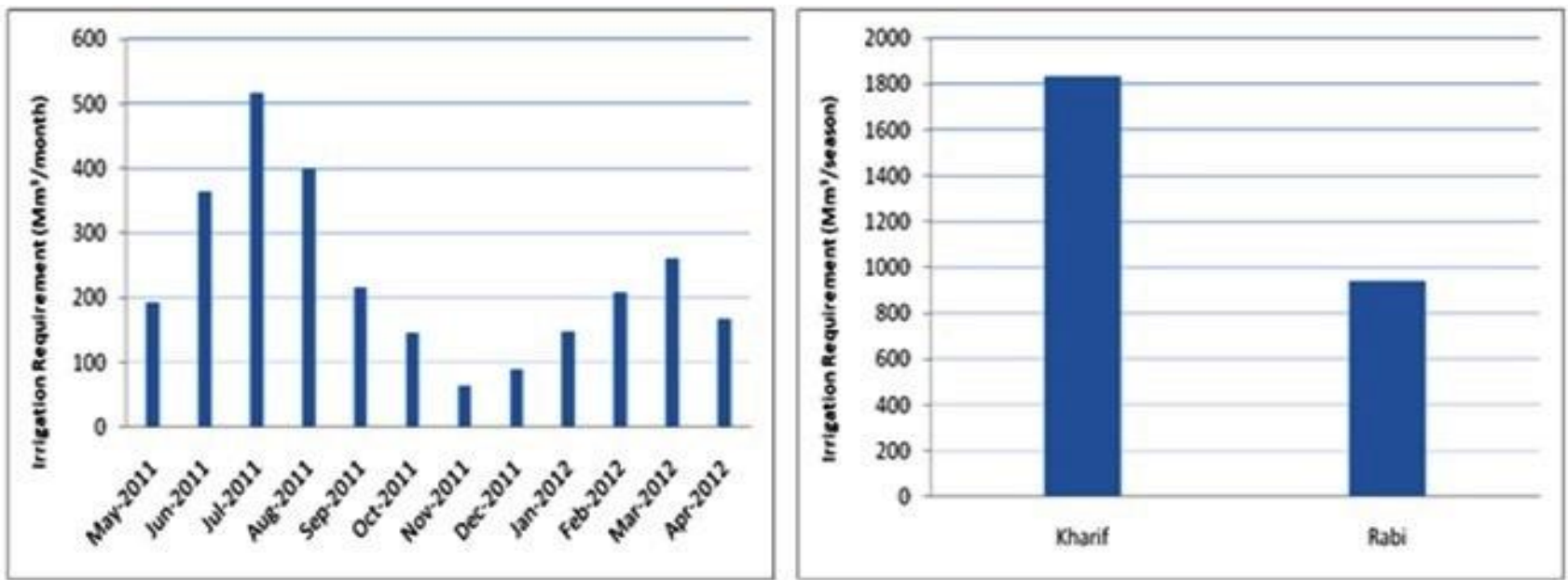

Figure 13. Estimated annual and seasonal crop water requirement

Conclusions: In the present study, a procedure for generating the LULC maps has been developed and demonstrated. The traditional mapping techniques are time consuming and laborious while LULC maps can be developed for specific regions using the latest satellite images that are economically available with acceptable resolution such as LANDSAT 7 ETM+. The results of present study showed that the use of $30 \mathrm{~m}$ LANDSAT 7 ETM+ images is important tool for crop identification and their areas in undersized agriculture regions like Pakistan. The accuracy of the developed LULC maps and associated results largely depends on the accuracy of the ground survey data and image classifications. In this study, 74\% accuracy was achieved using training and testing data through field validation which was close to officially statistics and field data. The regional LULC map of Multan was successfully used for regional irrigation water requirements calculations using the extracted cropped area. This seasonal crop maps and resulting irrigation water requirement relation can be used in decision making to full fill the water requirement of region. It was observed that cloud free images with maximum NDVI may increase the predicting accuracy.

\section{REFERENCES}

ADB. (2006). Proposed multitranche financing facility and technical assistance grant, Islamic Republic of Pakistan, Renewable Energy Development Sector Investment Program, Asian Development Bank. ADB project No. 40075-013 in Pakistan

Aplin, P., and P. M. Atkinson (2001). Sub-pixel land cover mapping for per-field classification. Intl. J. Remote Sensing. 22:2853-2858.

Asgarian, A., A. Soffianian, and S. Pourmanafi (2016). Crop type mapping in a highly fragmented and heterogeneous agricultural landscape: A case of central Iran using multi-temporal Landsat 8 imagery. Computers \& Electronics Agriculture. 127:531-540.

Barrett, R., P. Crowther, R. Laurence, and R. Lincolne (2000). Agricultural crop identification using SPOT and LANDSAT images in Tasmania. Intl. Archives Photogrammetry \& Remote Sensing. XXXIII(B7):133-139

Cai, Y., K. Guan, J. Peng, S. Wang, C. Seifert, B. Wardlow, and Z. Li (2018). A high-performance and inseason classification system of field-level crop types using time-series Landsat data and a machine learning approach. Remote Sensing Environment. 210:35-47.

Campbell, J. B (2008). GloVis as a resource for teaching geographic content and concepts. J. Geography. 106(6):239-251.

Cheema, M. J. M., and W.G.M. Bastiaanssen (2010). Land use and land cover classification in the irrigated Indus Basin using growth phenology information from satellite data to support water management analysis. Agri. Water Management. 97(10):15411552.

Chemin, Y., A. Platonov, M. Ul-Hassan, and I. Abdullayev (2004). Using remote sensing data for water depletion assessment at administrative and irrigation-system levels: case study of the Ferghana Province of Uzbekistan. Agri. Water Management. 64(3):183-196.

Coppin, P., E. Lambin, I. Jonckheere, and B. Muys (2004). Digital change detection methods in natural ecosystem monitoring: A review. In Analysis of multi-temporal remote sensing images. 3-36 p.

Fan, F., Q. Weng, Y. Wang (2007). Land use land cover change in Guangzhou, China, from 1998 to 2003, based on Landsat TM/ETM+ imagery. Sensors. (7):1323-1342. doi: 10.3390/s7071323.

FAO. (2001). Methodologies on crop water use and crop water productivity. Presented in Expert meeting on crop water productivity, Rome. Food and Agriculture Organization (FAO). 
FAO. (2012). Irrigation in Southern and Eastern Asia in figures. Food and Agriculture Organization (FAO), the United Nation.

Garcia, A. S., V. M. de FN Vilela, R. Rizzo, P. West, J. S. Gerber, P. M. Engstrom, and M. V. R. Ballester (2019). Assessing land use/cover dynamics and exploring drivers in the Amazon's arc of deforestation through a hierarchical, multi-scale and multi-temporal classification approach. Remote Sensing Applications: Society and Environment. 15:100-233.

GOP. (2012). Pakistan bureau of statistics, Government of Pakistan (GOP), Islamabad.

GoP. (2016). Punjab Development Statistics, Bureau of Statistics, Government of Punjab (GoP), Lahore.

GoP. (2010). Punjab Development Statistics (PDS), Bureau of Statistics, Government of Punjab (GoP), Lahore.

Hargreaves, G. H. and Z. A. Samani (1985). Reference crop evapotranspiration from temperature. Applied engineering in agriculture 1(2):96-99.

Hassan, Z., R. Shabbir, S. S. Ahmad, A. H. Malik, N. Aziz, A. Butt and S. Erum (2016). Dynamics of land use and land cover change (LULCC) using geospatial techniques: a case study of Islamabad Pakistan. Springer plus. 5(1): 812. doi: 10.1186/s40064-016-2414-z

Imagine. (2006). ERDAS IMAGINE® Tour Guides ${ }^{\mathrm{TM}}$. Leica Geosystems. $730 \mathrm{p}$.

Jin, X., Y. Jin, D. Yuan, and X. Mao (2019). Effects of landuse data resolution on hydrologic modelling, a case study in the upper reach of the Heihe River, Northwest China. Ecological Modelling. 404:6168.

Joseph, G. (2005). Fundamentals of remote sensing. 2nd ED. Universities Press; Ahmadabad (India). 145 p.

Koneti, S., , S. L. Sunkara and P. S. Roy (2018). Hydrological Modelling with Respect to Impact of Land-Use and Land-Cover Change on the Runoff Dynamics in Godavari River Basin Using the HEC-HMS Model. ISPRS Intl. J. Geo-Inf. 7(6): 206. https://doi.org/10.3390/ ijgi7060206

Li, C., H. Li, J. Li, Y. Lei, C. Li, K. Manevski, and Y. Shen (2019). Using NDVI percentiles to monitor realtime crop growth. Computers \& Electronics in Agri., 162:357-363.

Liu, X. and Y. Ding (2018). Auxiliary pixel data selection for recovering Landsat ETM+ SLC-off images. The Egy. J. Remote Sensing Space Sci., 21(3):273-284.

Lobell, D. B., D. Thau, C. Seifert, E. Engle, and B. Little (2015). A scalable satellite-based crop yield mapper. Remote Sensing of Environment. 164:324-333.

Muttitanon, W., and N. K. Tripathi (2005). Land Use/Land Cover changes in the Coastal Zone of Ban Don Bay, Thailand using Landsat 5 TM data. Intl. J. Remote Sensing 26(11):2311-2323.
Naheed, G., and G. Rasul (2010). Recent water requirement of cotton crop in Pakistan. Pakistan J. Meteorology. 6(12):75-84.

Panigrahy, S., G. Upadhyay, S. S. Ray, and J. S. Parihar (2010). Mapping of cropping system for the IndoGangetic plain using multi-date SPOT NDVI-VGT data. J. Indian Society Remote Sensing. 38(4):627632.

Rawat, K. S. and S. K. Singh (2017). Estimation of Surface Runoff from Semi-arid Ungauged Agricultural Watershed Using SCS-CN Method and Earth Observation Data Sets Water Conser. Sci. Engineering. 1(4): 233-247.

Rehman, A., L. Jingdong, B. Shahzad, A. A. Chandio, I. Hussain, G. Nabi, and M. S. Iqbal (2015). Economic perspectives of major field crops of Pakistan: An empirical study. Pacific Sci. Review B: Humanities \& Social Sci., 1(3):145-158.

Shrestha, B. B. (2019). Approach for Analysis of LandCover Changes and Their Impact on Flooding Regime. Quaternary. 2(3): 27. https://doi.org /10.3390/ quat 2030027

Song, X. P., P. V. Potapov, A. Krylov, L. King, C. M. Di Bella, A. Hudson, A. Khan, B. Adusei, S. V. Stehman, and M. C. Hansen (2017). National-scale soybean mapping and area estimation in the United States using medium resolution satellite imagery and field survey. Remote Sensing Environ., 190:383-395.

Toomanian, A., A. Gieske, and M. Akbari (2004). Irrigated area determination by NDVI-Landsat upscaling techniques, Zayandeh River Basin, Esfahan, Iran. Intl. J. Remote Sensing. 15:4945-4960.

Turner, G. M., T. M. Baynes, and B. C. McInnis (2010). A water accounting system for strategic water management. Water resources management. 24(3):513-545.

Ullah, M. K., Z. Habib, and S. Muhammad (2001). Spatial distribution of reference and potential evapotranspiration across the Indus Basin Irrigation Systems. 24.

Usman, M., R. Liedl, A. M. Shahid, A. Abbas (2016). Land use/land cover classification and its change detection using multi-temporal MODIS NDVI data. J. Geog. Sci., 25(2):1479-1506. doi: $10.1007 / \mathrm{s} 11442-015-1247-\mathrm{y}$

USGS. (2004). SLC-off Gap-Filled Products Gap-Fill Algorithm Methodology. Phase 2 Gap-Fill Algorithm. US Geological Survey (USGS) Earth Resources Observation and Science Center. https://landsat.usgs.gov/sites/default/files/documen ts/L7SLCGapFilledMethod.pdf

Waldner, F., S. Fritz, A. Di Gregorio, D. Plotnikov, S. Bartalev, N. Kussul, P. Gong, P. Thenkbail, G. Hazeu, I. Kalien, F. Low, J. Miettinen, V. K. Dadhwal, C. Lamarche, S. Bontemps, and P. Defourny (2016). A unified cropland layer at 250 $\mathrm{m}$ for global agriculture monitoring. Data. 1(1): 3 . 